\title{
Mechanical Bowel Preparation: Are We Ready for a Paradigm Shift?
}

\author{
Somprakas Basu Vijay Kumar Shukla \\ Department of General Surgery, Institute of Medical Sciences, Banaras Hindu University, Varanasi, India
}

Colorectal surgery is still a challenge to the surgeon with respect to wound infection, intra-abdominal abscess and anastomotic leak. Since these complications are mainly caused by endogenous colonic bacteria, it was always thought logical that reducing the fecal load and bacterial count would reduce the rate of complications. This led to the concept of bowel antisepsis and cleansing in the 1940s and was accepted as a dogma in the 1970s. Since then various techniques of bowel preparation, the agents used and the modus operandi have changed many times. Such rapid changes indicate that either the surgeons are not uniformly happy with the procedure or are still looking for an ideal agent.

Although traditionally mechanical bowel preparation (MBP) had its proposed advantages and shortcomings which were matter of some debate, its true role was never assessed through the eyes of evidence-based medicine. Hughes [1] (1972) was the first to challenge its longclaimed beneficial role when MBP was an incontestable routine. It was followed by a flurry of randomized controlled trials (RCTs) in the last two decades scrutinizing the role of $\mathrm{MBP}$ in elective colorectal surgery. Interestingly, all had concluded that MBP does not have any significant advantage in decreasing complications of colorectal surgery. Researchers went on further to prove that MBP actually increases infectious complications and anastomotic leaks and causes significant morphological and inflammatory changes in the colonic mucosa [2]. These were evidence enough to abandon it as a routine, which however actually did not happen. On the contrary, serious questions were raised on the accuracy of these RCTs. Unfortunately, none of these actually met the CONSORT guidelines completely.

A historic meta-analysis by Bucher et al. [3] evaluating seven RCTs concluded that there was no evidence to support the use of MBP in patients undergoing elective colorectal surgery. Though it was the highest form of evidence, it was not devoid of technical errors and the outcome analysis was conflicting and incongruent. More recent multicentric randomized trials are better structured, however, and statistically robust. To name a few, a multicentric trial from Sweden which accrued 1,505 patients to give the study almost the desired power failed to demonstrate any significant benefit of MBP in reducing wound infection, overall infection and relaparotomy rate [4]. A systematic review by Guenaga et al. [5] done with meticulous selection of studies to prevent bias and type II error concluded that prophylactic MBP was not beneficial for the patients and controversially the bowel preparation might lead to more anastomotic leakage. Though it was not a part of consensus statement, the authors recommended such procedure should be omitted. In a multicenter randomized trial by Contant et al. [6], the rate of anastomotic leakage did not differ significantly between with and without MBP groups $(\mathrm{p}<0.69)$. Although other septic complications, fascial dehiscence and mortality did not differ, those with MBP had fewer abscesses after anastomotic leakage $(\mathrm{p}<0.001)$. In another novel study,

\section{KARGER}

Fax +4161306 1234 E-Mail karger@karger.ch www.karger.com (c) 2008 S. Karger AG, Basel

0253-4886/08/0255-0325\$24.50/0

Accessible online at:

www.karger.com/dsu
Dr. Somprakas Basu, MS

Department of General Surgery, Institute of Medical Sciences

Banaras Hindu University

Varanasi 221005 (India)

Tel. +91 933547 9735, Fax +91 542236 8163, E-Mail sombasu@hotmail.com 
questionnaires evaluating multiple subjective symptoms arising from MBP were assessed among patients [7]. Interestingly, though the time to postoperative oral intake did not differ, bowel emptying occurred earlier in the noMBP group. Overall, the patients expressed significant distress to MBP. Thus, as more and more evidence has accrued, the role of MBP has faced a big challenge with some authorities saying it is unnecessary, while others think it may actually harm.

In the midst of these newer observations, one pertinent query remains. Polyethylene glycol (PEG) has been used for bowel preparation in most of these RCTs/multicenter trials. The outcome of using other agents like sodium phosphate or picosulfate in bowel preparation is not adequately known in comparison to PEG. This makes one ask 'is it the procedure which is at fault or the agent?' This is reflected in a meta-analysis by Slim et al. [8], which included 11 trials and focused on the methodological qualities and congruent outcome measures like anastomotic leak and septic complications. They observed significantly higher anastomotic leakage after MBP. All other endpoint analyses also favored a no-preparation approach without a significant difference. Interestingly, subgroup analysis showed that anastomotic leakage was significantly greater after bowel preparation with PEG compared to no preparation but not after other types of preparation. Although the authors conclude with evidence in favor of omitting MBP, they also make a point regarding comparison of other bowel preparations with PEG. A recent trial by Itani et al. [9] comparing PEG with sodium phosphate concluded that bowel preparation with sodium phosphate is superior. Another recent review by Nichols et al. [10] (2005) concluded that MBP has still a high potential of decreasing infective complication rate, and it works best when combined with preoperative oral and perioperative parenteral prophylactic antibiotics. These observations indicate that surgeons are still not ready to forego bowel preparation, which has been practiced as a dogma for more than half a century and continue to search for the ideal agent.

The role of MBP in rectal surgeries has not been adequately addressed to. As most of the studies involve colonic resections and few studies have focused only on rectal resections, the body of evidence is inadequate for decision-making. Traditionally, rectal washouts were common and are still widely practiced. Bretagnol et al. [11], in a nonrandomized study, compared 51 consecutive patients with rectal resection without MBP to a matched group of 61 controls with MBP. Although the overall morbidity was higher in the MBP group, the rate of anas- tomotic leakage was similar ( 8 vs. $10 \% ; p=1.000)$. Interestingly, peritonitis occurred more, though not significantly, in the no-MBP group, and a trend toward higher infectious complications was noted in the MBP group. Another nonrandomized retrospective study $(\mathrm{n}=144)$ from the Netherlands, which included low anterior resections without MBP, reported a less than $5 \%$ anastomotic leakage rate as compared to a leakage rate of up to $18 \%$ in studies using MBP [12]. Though this study is weak and noncomparative, it is worth mentioning that surgeons from different corners are trying to evaluate the outcome of rectal resections without MBP. At present, it is too premature to comment anything in this regard. More evidence in the form of multicenter trials is required for evaluation of role of MBP in rectal surgery.

With the rise of laparoscopic resection for colon cancers, the role of MBP needs to be defined in this arena. Although data are inadequate, attempts have been made to evaluate this complex situation. In a retrospective study by Zmora et al. [13], patients with and without MBP, who underwent laparoscopic colectomy, were compared. There was no statistical difference between the two groups with regard to postoperative infective complications and anastomotic leak rate, indicating that laparoscopic colectomy can safely be performed without MBP. Larger prospective trials, however, are required to come to safe conclusions. Since, depending on situation, the laparoscopic technique may vary, e.g. a purely laparoscopic approach or a laparoscopic-assisted approach or even a laparoscopic hand-assisted surgery especially when the tumor needs intraoperative palpation and localization, it is difficult to make comparisons on equal grounds as the studies tend to be lengthy and time-consuming particularly when conversion rate is high.

It is intriguing that despite adequate evidence, recommendation to abandon MBP as a routine still fails to find place in the guidelines of various surgical societies (Association of Coloproctology of Great Britain and Ireland, 2001 [14], The guidelines of the Clinical Standards Board of Scotland in 2003 [15]). In 1997, it was observed that $100 \%$ of American colorectal surgeons used MBP prior to colorectal surgery [16]. A survey of the American colorectal surgeons in 2001 revealed that $46 \%$ used sodium phosphate, 32\% used PEG and 15\% selectively alternated between the two [17]. Another survey of five northern European countries (2005) showed that $75 \%$ surgeons used MBP [18]. These practices among surgeons globally indicate that preoperative bowel preparation is still very much in vogue, in spite of recent data accumulating against it. This is probably because irrespective of geographical dis- 
tribution surgeons are mostly dogmatic in their habits and are reluctant to change. Absence of a strong recommendation is thus reflected in their continued practice of MBP.

Thus, it seems the surgical fraternity is not yet unanimously ready to abandon bowel preparation in elective colorectal surgery. Though most surgeons world over still practice bowel preparation of some form and believe in its beneficial role, recent good evidence points otherwise and is still accumulating. As of now, we stand on the crossroad and are uncertain whether we are slowly facing a paradigm shift as far as MBP is concerned. Despite evidence gathering momentum, it is restricted to a few centers or authorities or academic institutes, and is yet to become a universal phenomenon. For this to happen, recommendation for abandoning MBP needs to find a place in the guidelines of various surgical societies. We have to wait some more time to know whether it continues to hold its place or is abandoned as a practice of the past. As of now, we can only hope for consensus statements backed by good level of evidence in future so that morbidity of the patients undergoing colorectal surgery is not unduly increased.

\section{Conflict of Interest}

Nil.

\section{References}

1 Hughes E: Asepsis in large-bowel surgery. Ann R Coll Surg Engl 1972;51:347-356.

-2 Bucher P, Gervaz P, Egger J, Soravia C, Morel P: Morphologic alterations associated with mechanical bowel preparation before elective colorectal surgery: a randomized trial. Dis Colon Rectum 2005;49:109-112.

-3 Bucher P, Mermillod B, Gervaz P, Morel P: Mechanical bowel preparation for elective colorectal surgery. A meta-analysis. Arch Surg 2004;139:1359-1364.

4 Jung B, Pahlman L, Nystrom PO, Nilsson E; Mechanical Bowel Preparation Study Group: Multicenter randomized clinical trial of mechanical bowel preparation in elective colonic resection. Br J Surg 2007;94:689-695.

5 Guenaga K, Attalah AN, Castro AA, Matos DDM, Wille-Jørgensen P: Mechanical bowel preparation for elective colorectal surgery. Cochrane Database of Systematic Reviews 2005, Issue 1, Art No CD001544. DOI: 10.1002/14651858.CD001544.pub2.

-6 Contant CM, Hop WC, van't Sant HP, et al: Mechanical bowel preparation for elective colorectal surgery: a multicenter randomized trial. Lancet 2007;370:2112-2117.
$>$ Jung B, Lannerstad O, Pahlman L, Arodell M, Unosson M, Nilsson E: Preoperative mechanical preparation of the colon: the patient's experience. BMC Surg 2007;7:5.

8 Slim K, Vicaut E, Panis Y, Chipponi J: Metaanalysis of randomized clinical trials of colorectal surgery with or without mechanical bowel preparation. Br J Surg 2004;91: $1125-1130$.

9 Itani KM, Wilson SE, Awad SS, Jensen EH, Finn TS, Abramson MA: Polyethylene glycol versus sodium phosphate mechanical bowel preparation in elective colorectal surgery. Am J Surg 2007;193:190-194.

10 Nichols RL, Choe EU, Weldon CB: Mechanical and antibacterial bowel preparation in colon and rectal surgery. Chemotherapy 2005;51(suppl 1):115-121.

-11 Bretagnol F, Alves A, Ricci A, Valleur P, Panis Y: Rectal cancer surgery without mechanical bowel preparation. Br J Surg 2007; 94:1266-1271.

12 Vlot EA, Zeebregts CJ, Gerritsen JJ, Mulder HJ, Mastboom WJ, Klaase JM: Anterior resection of rectal cancer without bowel preparation and diverting stoma. Surg Today 2005 ; 35:629-633.

13 Zmora O, Lebedyev A, Hoffman A, et al: Laparoscopic colectomy without mechanical bowel preparation. Int J Colorectal Dis 2006;21:683-687.
14 The Association of Coloproctology of Great Britain and Ireland. Guidelines for the management of colorectal cancers (2001). Guidelines for the management of colorectal cancers. London: The Association of Coloproctology of Great Britain and Ireland, 2001

15 Management of colorectal cancer: a national guideline. Scottish Intercollegiate Guidelines Network, March 2003

16 Nichols RL, Smith JW, Garcia RY, Waterman RS, Holmes JWC: Current practices of preoperative bowel preparation among North American colorectal surgeons. Clin Infect Dis 1997;24:609-619.

-17 Zmora O, Wexner S, Hajjar L, et al: Trends in preparation for colorectal surgery: survey of the members of the American Society of Colon and Rectal Surgeons. Am Surg 2003;69: $150-154$.

18 Lassen K, Hannemann P, Ljungqvist O, et al: Patterns in current perioperative practice: survey of colorectal surgeons in five northern European countries. Br Med J 2005;330: 1420-1421. 


\section{Invited Commentary \\ Mechanical Bowel Preparation before Colorectal Surgery?}

Andreas Thalheimer, Christoph T. Germer

Department of Surgery, University Hospital of Würzburg, Würzburg, Germany

Are we ready for a paradigm shift? Basu and Shukla [1] try to answer this question in today's issue of Digestive Surgery by bringing together the results of numerous studies that, in short, do not demonstrate a benefit for mechanical bowel preparation (MBP) before colorectal surgery.

The historically grown and generally accepted consensus that preoperative bowel lavage is beneficial for patients undergoing colorectal resection in terms of reducing the rate of anastomotic leakage has never been clearly verified. On the contrary, several randomized controlled studies (RCT) have shown the uselessness or even the adverse impact of MBP on the postoperative course following colorectal resection. Nonetheless, MBP is still widely used by colorectal surgeons throughout the world. This is explained by questioning the study design and accuracy of the RCT published in the past. Consequently, the meta-analysis which has gathered the data of the mentioned RCT and which has shown that anastomotic leaks occurred more often after MBP (5.1 vs. 2.6\%) [2] has been challenged by proponents of MBP.

Two recently published randomized controlled studies with more than 1,400 [3] and 1,300 [4] patients, respectively, comparing the outcome of colorectal surgery with and without mechanical bowel lavage clearly support the anti-MBP frontline. In both trials the occurrence of clinically significant anastomotic leaks was similar in patients who underwent colorectal surgery with or without MBP. But even these trials are questioned concerning endpoint definition, surgical standardization and statis- tical design. It seems as if sceptical empiricism sometimes controls decision-making in medicine more than it should.

When arguing over this issue, it is necessary to point out that it seems to be oversimplified to restrict the problem to surgical problems around anastomotic leakage. There are increasing data indicating that MBP itself is harmful not only to patient comfort but also because it causes severe side-effects such as electrolyte or acid-base imbalances and dehydration [5].

Summing up, there are a number of good reasons for questioning the necessity of preoperative bowel preparation. Most likely the omission of MBP before colorectal surgery will sooner or later be widely accepted, particularly in the context of fast-track perioperative patient management.

\section{References}

1 Basu S, Shukla VK: Mechanical bowel preparation: are we ready for a paradigm shift? Dig Surg 2008;25:325-328.

2 Bucher P, Gervaz P, Morel P: Should preoperative mechanical bowel preparation be abandoned? Ann Surg 2007;245:662.

3 Contant CM, Hop WC, van't Sant HP, Oostvogel HJ, Smeets HJ, Stassen LP, Neijenhuis PA, Idenburg FJ, Dijkhuis CM, Heres P, van Tets WF, Gerritsen JJ, Weidema WF: Mechanical bowel preparation for elective colorectal surgery: a multicentre randomised trial. Lancet 2007;370: 2112-2117.

4 Jung B, Pahlman L, Nystrom PO, Nilsson E: Multicentre randomized clinical trial of mechanical bowel preparation in elective colonic resection. Br J Surg 2007;94:689-695.

5 Holte K, Nielsen KG, Madsen JL, Kehlet H: Physiologic effects of bowel preparation. Dis Colon Rectum 2004;47:1397-1402. 